\title{
Thermal comfort analysis of public transport passengers in Catania
}

\author{
F. Patania, A. Gagliano, F. Nocera \& A. Galesi \\ Department of Industrial and Mechanics Engineering, \\ Catania University, Italy
}

\begin{abstract}
The issue of passenger comfort on board public transport is gaining increasing importance in the last few years. Thermal comfort and indoor air quality are often a problem for the passengers during transportation.

This paper presents the results of measurements and thermal comfort analysis and indoor air quality to which passengers are exposed during the utilization of public transport of Catania city. To individuate the thermal comfort of passengers the following indices are used: gradient of temperature, PMV, RWI, $\mathrm{CO}_{2}$ and $\mathrm{CO}$ concentration, SSI and Humidex.

Keywords: heat-waves, bioclimatic index, air quality, public transport.
\end{abstract}

\section{Introduction}

Since the public transportation system is used by many passengers in a tightly enclosed space, it can cause adverse impacts on health due to poor indoor air quality and a lack of appropriate ventilation. Moreover, the heat generated by train motors, electric lighting, human bodies, etc is so significant that excessive temperatures would prevail in summer and this may lead to passenger discomfort and complaints if the environment is not cooled.

So, improving the comfort conditions of public transport is an important factor necessary to increase the attractiveness of the public transport systems

In particular, the air conditioning on subway passenger cabins or on the buses can play a very significant role in making public transport a worthwhile alternative to the private car. 
Among the many advantages of public transport, in terms of environmental social and economic benefits, we can list a few below:

- Reducing congestion;

- Improving the air quality;

- Reducing noise pollution;

- It is a stress-free alternative to the private car;

- Stimulating economic growth;

- It is convenient for families, businesses and the community;

- It is safe;

- It is always available;

- Saving time and money;

- Reducing the cost of living expenses.

So if we want the citizens to prefer public transport to the private car, it is necessary that subway passenger cabins and buses are equipped with facilities that guarantee a comfortable environment with regard to noise, light and thermohygrometric conditions.

Consequently, the authors have evaluated thermo-hygrometric comfort and indoor air quality to which passengers are exposed inside the public transport of Catania carrying out a measurement campaign on one bus route and subway route.

\section{The bioclimatic index}

The human thermoregulatory system can be separated into two interacting subsystems:

- controlling the active system which includes the thermoregulatory responses of shivering thermo genesis, sweat moisture excretion, and peripheral blood flow (cutaneous vasomotion) of unacclimatized subjects,

- $\quad$ the controlled passive system dealing with the physical human body and the heat transfer phenomena occurring in it and at its surface [1].

The heat exchange between the human body and the thermal environment can be described in the form of the energy balance equation.

$$
\begin{aligned}
& M-W-\left[Q_{H}\left(T_{a}, v\right)+Q\left(T_{m r t}, v\right)\right]-\left[Q_{L}\left(e_{v}, v\right)+Q_{s W}\left(e_{v}, v\right)\right]- \\
& -Q_{R E}\left(T_{a}, e_{v}\right) \pm S_{a}=0
\end{aligned}
$$

The human thermal environment cannot be represented adequately with just a single parameter so more than 100 simple thermal indices have been developed; most of them are two-parameter indices.

The bioclimatic indices most commonly used in urban climate studies, to quantify the discomfort in summer season, are the Humidex, the new Summer Simmer Index (SSI), the Fanger Indices, the Relative Warmth Index (RWI), the apparent temperature and so on. 


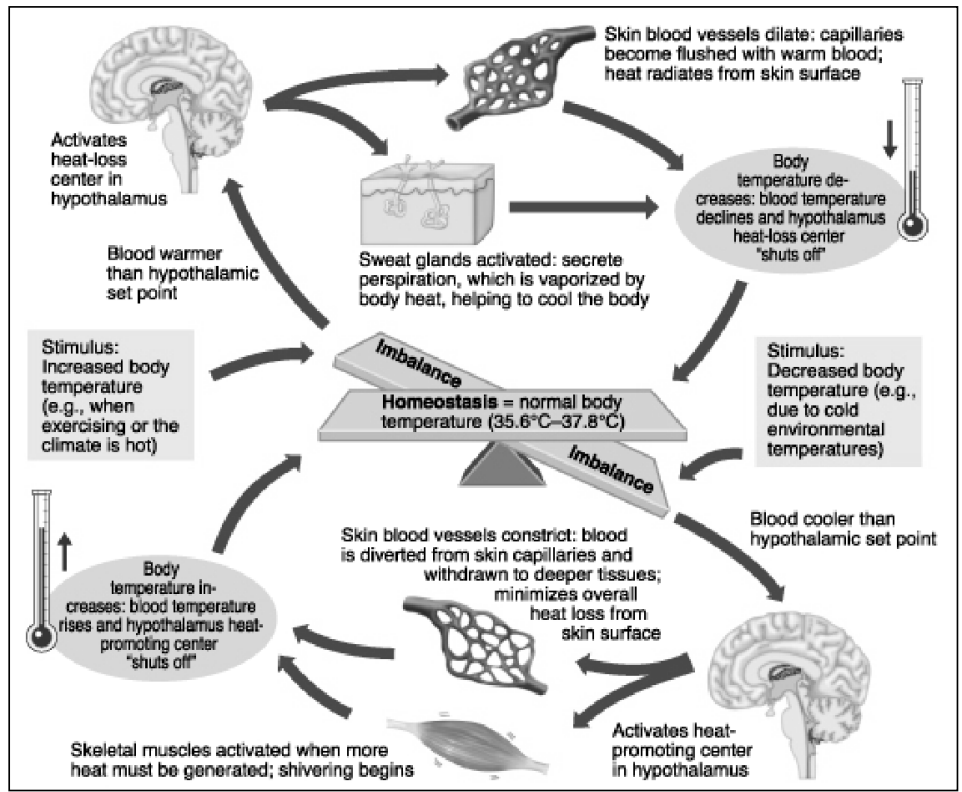

Figure 1: Human physiological and behavioural thermoregulation (Cummings 2001).

The Humidex was created by Masterton and Richardson [2] to quantify and include the degree of risk for the human body in the event of heat and excessive moisture.

$$
\begin{gathered}
\text { Humidex }=\mathrm{T}_{\mathrm{a}}+\frac{5}{9} \times \mathrm{e}^{-10} \\
\left.\mathrm{e}=\left(6.112 \times 10^{\left(7.5 \times \mathrm{T}_{\mathrm{a}} /\left(237.7+\mathrm{T}_{\mathrm{a}}\right)\right.}\right) \times \mathrm{H} / 100\right)
\end{gathered}
$$

Table 1 shows the correlation between the values of the Humidex and the correlated human discomfort. The new Summer Simmer Index (SSI) was presented in California in January 2000. It uses the results from physiological models and human trials conducted over a period of more than 75 years by the American Society of Heating and Refrigeration Engineering (ASHRAE) at the University of Kansas.

The new Summer Simmer Index (SSI) describes the conditions of heat stress during hot weather and its formula is:

$$
\mathrm{SSI}=1.98 \times\left\{\left[\mathrm{T}_{\mathrm{a}}-(0.55-0.0055 \times(\mathrm{H})] \times\left(\mathrm{T}_{\mathrm{a}}-58\right)\right\}-56.83\right.
$$

Seven zones have been identified to describe the thermal sensation of the SSI Index. 
Table 1: $\quad$ Humidex and the correlated human discomfort.

\begin{tabular}{cc}
\hline Humidex range & Degree of comfort \\
\hline $20-29$ & comfortable \\
\hline $30-39$ & some discomfort \\
\hline $40-45$ & great discomfort; avoid exertion \\
\hline above 45 & dangerous \\
\hline above 54 & heat stroke imminent \\
\hline
\end{tabular}

Table 2: $\quad$ Thermal sensation of the SSI Index.

\begin{tabular}{ccc}
\hline Zone & SSI & Thermal sensation \\
\hline 1 & from 70 to 77 & Most people are comfortable, but slightly cool \\
\hline 2 & from 77 to 83 & Nearly everyone feels quite comfortable \\
\hline 3 & from 83 to 91 & Most people are comfortable, but slightly warm \\
\hline 4 & from 91 to & Increasing discomfort(warm) \\
\hline 5 & from 100 & to \\
112 & $\begin{array}{c}\text { A caution of sunstroke and heat exhaustion exists for } \\
\text { prolonged exposure and activity, along with } \\
\text { significant discomfort (extremely warm) }\end{array}$ \\
\hline 6 & from 112 to & $\begin{array}{c}\text { Virtually everyone is uncomfortable, a danger of } \\
\text { heatstroke and great discomfort exists (hot) }\end{array}$ \\
\hline 7 & from 125 to & $\begin{array}{c}\text { There is an extreme danger of heatstroke, especially } \\
\text { for the weakened or elderly, and even young } \\
\text { children, whose body metabolism demands cooler } \\
\text { effective temperatures than most adults. Maximum } \\
\text { discomfort exists at these conditions (extremely } \\
\text { hot). }\end{array}$ \\
& 150 & $\begin{array}{c}\text { Beyond 150, circulatory collapse is imminent for } \\
\text { prolonged exposure }\end{array}$ \\
& &
\end{tabular}

Obviously the formulas used to calculate the discomfort indices produce theoretic average data which may be highly influenced by a lot of human and environmental factors such as: height, weight and sex of the individual, clothes used, presence of shade or wind, carried out activity.

In order to evaluate the thermal comfort with Fanger's Indices, the authors have adopted the PMV and PPD Indices according to the International Standard ISO 7730 [3]. The Predicted Mean Vote (PMV) is the mean vote expected to arise from averaging the thermal sensation vote of a large group of people in a given environment. PMV is derived from the physics of heat transfer combined with an empirical fit to sensation. PMV establishes a thermal strain based on steady-state heat transfer between the body and the environment and assigns a comfort vote to that amount of strain. The PMV is a complex mathematical expression involving activity, clothing and the four environmental parameters. It is expressed by: 


$$
\mathrm{PMV}=\left(0,303 \mathrm{xe}^{-0,036 \mathrm{M}}+0,028\right) \mathrm{L}
$$

in which $\mathrm{M}$ is metabolic rate $\left(\mathrm{W} / \mathrm{m}^{2}\right)$ and $\mathrm{L}(\mathrm{W})$ is thermal load defined as the difference between the internal heat production and the heat loss to the actual environment for a person hypothetically kept at comfort values of skin temperature and evaporative heat loss by sweating at the actual activity level.

The term Predicted Percentage Dissatisfied (PPD) is a quantitative measure of the thermal discomfort of a group of people at a particular thermal environment.

Table 3: $\quad$ PMV Index classification.

\begin{tabular}{cc}
\hline PMV value & Sensation \\
\hline+3 & Hot \\
\hline+2 & Warm \\
\hline+1 & Slightly warm \\
\hline 0 & comfortable \\
\hline-1 & Slightly cool \\
\hline-2 & cool \\
\hline-3 & cold \\
\hline
\end{tabular}

The PPD is related to the PMV as follows:

$$
\mathrm{PPD}=100-95 \mathrm{e}^{-\left(0,03353 \mathrm{PMV}^{4}+0,2179 \mathrm{PMV}^{2}\right)}
$$

The Relative Warmth Index (RWI) was proposed by the Transportation Air Conditioning Committee of American Society of Heating, Refrigerating and AirConditioning Engineers (ASHRAE) for thermal comfort design and investigation in a metro environment [4].

The RWI is a function of various parameters, including temperature, relative humidity, air velocity, individual clothing, and metabolic rate [5]. ASHRAE also proposed the thermal comfort classification table associated with RWI [6, 7].

Table 4: $\quad$ ASHRAE comfort classification using RWI.

\begin{tabular}{cc}
\hline RWI value & Sensation \\
\hline 0,25 & Warm \\
\hline 0,15 & Slightly warm \\
\hline 0,08 & Comfortable \\
\hline 0,00 & Slightly cool \\
\hline
\end{tabular}

The authors have adopted the following expression of RWI [5]:

$$
\begin{aligned}
& R W I=\frac{M\left(I_{c w}+I_{a}\right)+1,13(t-95)+R_{a}}{70(1,73-P)} \text { with }\left(p_{v}>0,67 \text { in } \mathrm{Hg}\right) \\
& R W I=\frac{M\left(I_{c W}+I_{a}\right)+1,13(t-95)+R I_{a}}{74,3} \text { with }\left(p_{v} \leq 0,67 \text { in } H g\right)
\end{aligned}
$$


where:

$\mathrm{M}=$ metabolic rate, $\mathrm{Btu} / \mathrm{h} \cdot \mathrm{ft}^{2}$

$\mathrm{I}_{\mathrm{cw}}=$ insulation of clothing based on wet cloth assumption, clo coefficient

$\mathrm{I}_{\mathrm{a}}=$ insulation effect of air boundary layer, clo coefficient

$\mathrm{t}=$ dry-bulb air temperature, ${ }^{\circ} \mathrm{F}$

$\mathrm{t}-95=$ difference between dry-bulb temperature and average skin temperature just before a person feels uncomfortably warm, ${ }^{\circ} \mathrm{F}$

$\mathrm{R}=$ mean incident radiant heat from sources other than walls at room temperature, Btu/h. $\mathrm{ft}^{2}$

$\mathrm{P}=$ vapor pressure of water in air, of mercury saturated vapor pressure $\left(\mathrm{Ps}_{\mathrm{s}}\right)$ and vapor pressure $\left(\mathrm{Pv}_{\mathrm{v}}\right)$ at $t$ were estimated using equations (9) and (10) [8]

$$
\begin{gathered}
\log \mathrm{P}_{\mathrm{s}}=30,59051-8,2 \cdot \log \mathrm{T}+2,4804 \cdot 10^{-3} \mathrm{~T}-\frac{3142,31}{\mathrm{~T}} \\
\mathrm{P}_{\mathrm{v}}=\mathrm{P}_{\mathrm{sl}}-1013,25 \cdot 6,66 \cdot 10^{-4} \cdot\left(\mathrm{t}-\mathrm{t}_{\mathrm{sl}}\right)
\end{gathered}
$$

where:

$\mathrm{P}_{\mathrm{S}}=$ saturated vapor pressure at temperature $\mathrm{t}$, $\mathrm{kpa}$

$\mathrm{P}_{\mathrm{sl}}=$ saturated vapor pressure at wet bulb temperature

tsl using equation (2), kpa

$\mathrm{P}_{\mathrm{V}}=$ vapor pressure at dry bulb temperatures, $\mathrm{kpa}$

$\mathrm{T}=$ absolute temperature, $\mathrm{K}$

$\mathrm{t}_{\mathrm{sl}}=$ wet bulb temperature, ${ }^{\circ} \mathrm{C}$

$\mathrm{t}=$ dry bulb temperature, ${ }^{\circ} \mathrm{C}$.
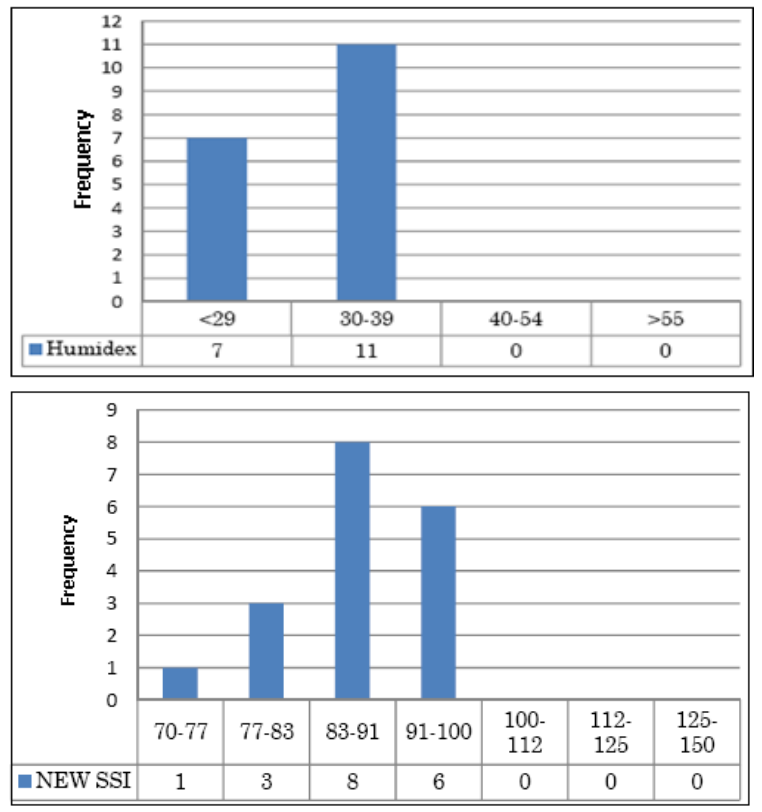

Figure 2: Frequency distributions of the Humidex and SSI Index inside the subway carriage. 


\section{The Indoor Air Quality (IAQ)}

The authors have selected $\mathrm{CO}$ and $\mathrm{CO}_{2}$ as a surrogate indicator because their concentrations in an indoor environment are good indicators of the effectiveness of a ventilation system and the adequacy of ventilation and they are suitable to evaluate the air quality on board public transport.

Carbon monoxide is an odorless, colorless and toxic gas. At lower levels of exposure, $\mathrm{CO}$ causes mild effects that are often mistaken for the flu [9]. These symptoms include headaches, dizziness, disorientation, nausea and fatigue. The effects of $\mathrm{CO}$ exposure can vary greatly from person to person depending on age, overall health and the concentration and length of exposure.

The current Occupational Safety and Health Administration (OSHA) permissible exposure limit (PEL) for carbon monoxide is 50 parts per million (ppm) parts of air $\left(55\right.$ milligrams per cubic meter $\left(\mathrm{mg} / \mathrm{m}^{3}\right)$ as an 8 -hour timeweighted average (TWA) concentration.

The National Institute for Occupational Safety and Health (NIOSH) has established a recommended exposure limit (REL) for carbon monoxide of $35 \mathrm{ppm}\left(40 \mathrm{mg} / \mathrm{m}^{3}\right)$ as an 8 -hour TWA and $200 \mathrm{ppm}\left(229 \mathrm{mg} / \mathrm{m}^{3}\right)$ as a ceiling. The American Conference of Governmental Industrial Hygienists (ACGIH) has assigned carbon monoxide a threshold limit value (TLV) of $25 \mathrm{ppm}\left(29 \mathrm{mg} / \mathrm{m}^{3}\right)$ as a TWA for a normal 8-hour workday and a 40-hour workweek.
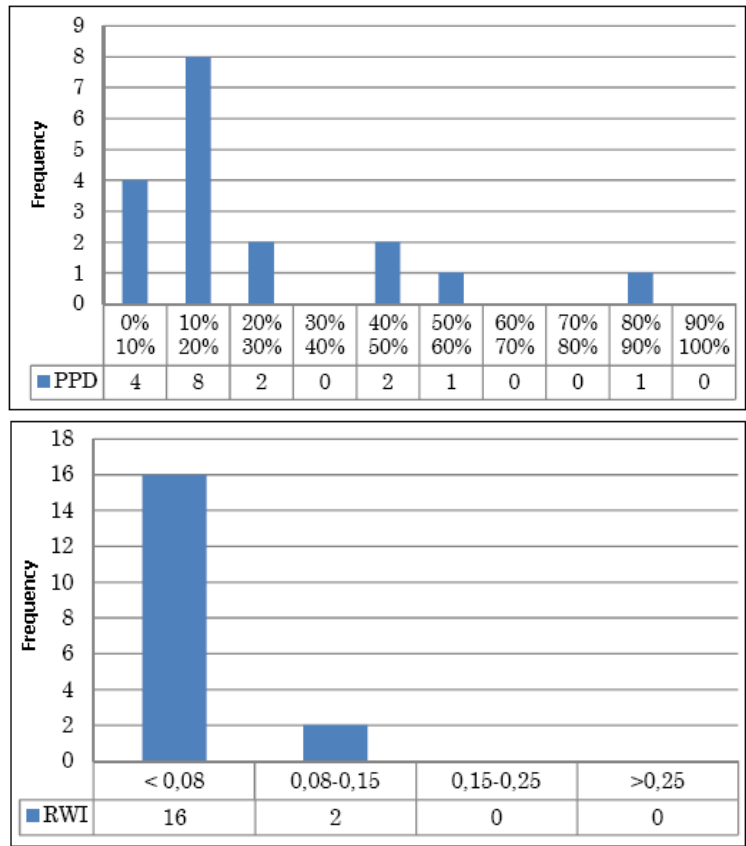

Figure 3: Frequency distributions of the PPD and RWI Index inside the metro. 

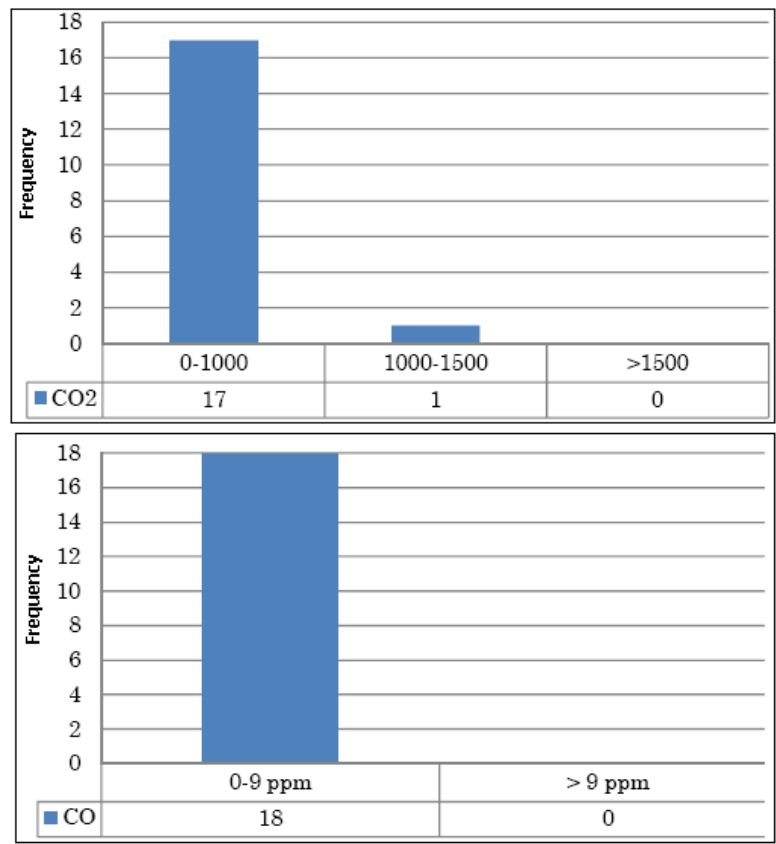

Figure 4: Frequency distributions of $\mathrm{CO}_{2}$ and $\mathrm{CO}$ index inside the subway carriage.

Carbon dioxide $\left(\mathrm{CO}_{2}\right)$ is a colourless, odourless, non-flammable gas that is a product of cellular respiration and burning of fossil fuels.

In terms of worker safety, Occupational Safety and Health Administration (OSHA) has set a permissible exposure limit (PEL) for $\mathrm{CO}_{2}$ of 5,000 parts per million (ppm) over an 8 -hour work day, which is equivalent to $0.5 \%$ by volume of air. Similarly, the American Conference of Governmental Industrial Hygienists (ACGIH) TLV (threshold limit value) is 5,000 ppm for an 8-hour workday, with a ceiling exposure limit of $30,000 \mathrm{ppm}$ for a 10 -minute period based on acute inhalation data.

Although normal levels of $\mathrm{CO}_{2}$ are considered harmless, under the right conditions, $\mathrm{CO}_{2}$ can cause adverse health effects [10].

\section{The survey methodology}

The authors have carried out a measurement campaign using a multi-gas monitor for confined space (Multirae Plus PGM 54) and a multifunction instrument for HVAC (Testo 450) systems. The authors have focused the research on subway line number $432(3.2 \mathrm{~km})$ and bus lines number 449 and $429(3.7 \mathrm{~km})$ of Catania City. While the subway carriages are air-conditioned, the buses are not equipped with an air conditioning system.

The measurements were carried out for 18 consecutive days in July at the following times: 8:30-9:30, 11:30-12:30, 15:30-16:30, 18:30-19:30. 


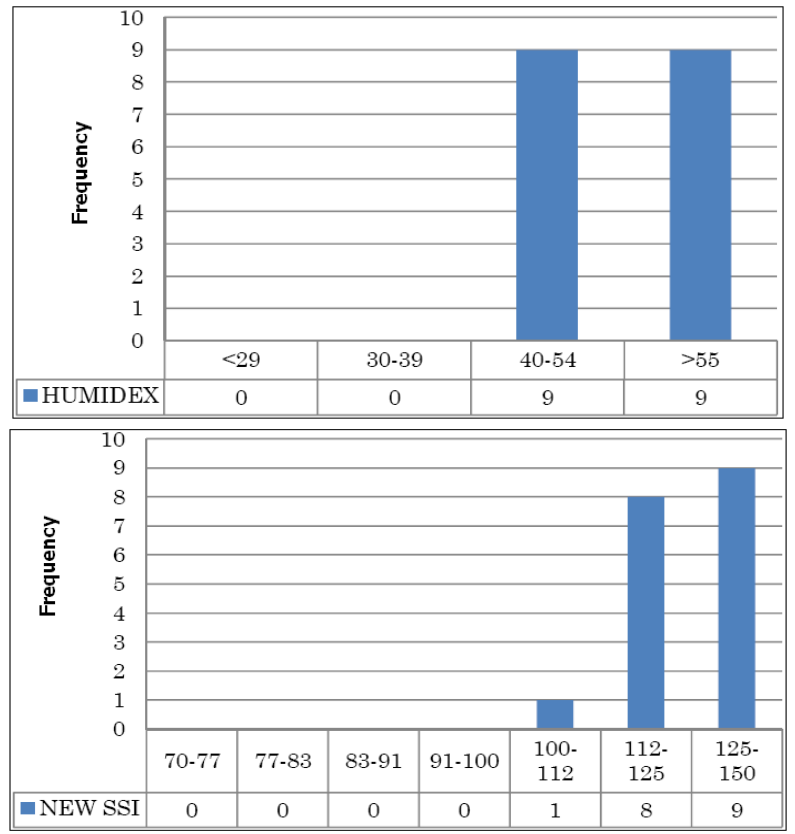

Figure 5: Frequency distributions of the Humidex and SSI Index inside the bus.

During each measurement the authors filled in a form in which they reported general data (route, date, time, travel time, waiting time of the stop, etc.), details of the vehicle (model, number of passenger, total seats) and other data (temperature, relative humidity, $\mathrm{CO}, \mathrm{CO}_{2}$ etc).

\section{The results}

Figure 2 shows the frequency distributions of the bioclimatic index inside a subway carriage.

It is noted that the Humidex Index has values lower than 29 in $39 \%$ of the cases evaluated, corresponding to a state of comfort, and values between 30 and 39 in $61 \%$ of the cases evaluated, corresponding to a state of some discomfort.

It is noticed that the SSI Index has values, in most cases $(78 \%)$ that indicate a condition of light physiological discomfort for the passengers while the other passengers perceive a condition of comfort.

It is interesting to notice that PPD Index shows that dissatisfied passengers are fewer than $10 \%$ in $20 \%$ of the cases evaluated. However, in most cases, although the PPD Index does not satisfy the limits of legislation, there is a relative low percentage of dissatisfaction that is included of between $10 \%$ and $30 \%$. 

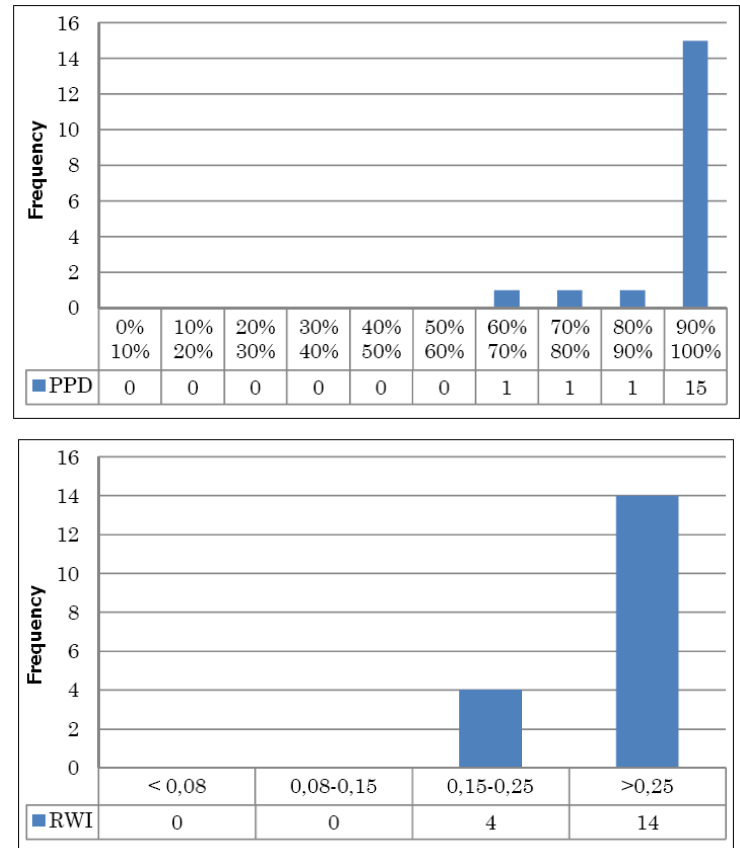

Figure 6: Frequency distributions of PPD and RWI Index inside the bus.

Regarding the RWI Index, it is noted that almost all measurements give values of sensation classifiable as "slightly cool" and only two measurements give values of sensation classifiable as "comfortable".

Figure 4 shows the frequency distributions of the IAQ Index inside a subway carriage.

Regarding the air quality, the results show that indices, in all measurements, do not exceed the legislation limit for both $\mathrm{CO}$ and $\mathrm{CO}_{2}$, with the exception of a measurement data due to overcrowding. bus.

Figure 5 shows the frequency distributions of the bioclimatic index inside the

It is noted that the Humidex Index has values corresponding to a state of strong physiological distress for $50 \%$ of the passengers and it has values that indicate the risk of an imminent heat stroke for the other $50 \%$ of the passengers.

The SSI Index assumes values that suggest physiological discomfort with some chance of heat stroke.

The PPD Index shows, in almost all measurements, a percentage of dissatisfaction comprising between $90 \%$ and $100 \%$.

Regarding the RWI Index, it is noted that all measurements give values of sensation classifiable as "slightly warm" or "warm".

Figure 7 shows the frequency distributions of the IAQ Index inside the bus.

Regarding the air quality, the results show that indices, in all measurements, do not exceed the legislation limit for both $\mathrm{CO}$ to $\mathrm{CO}_{2}$. 

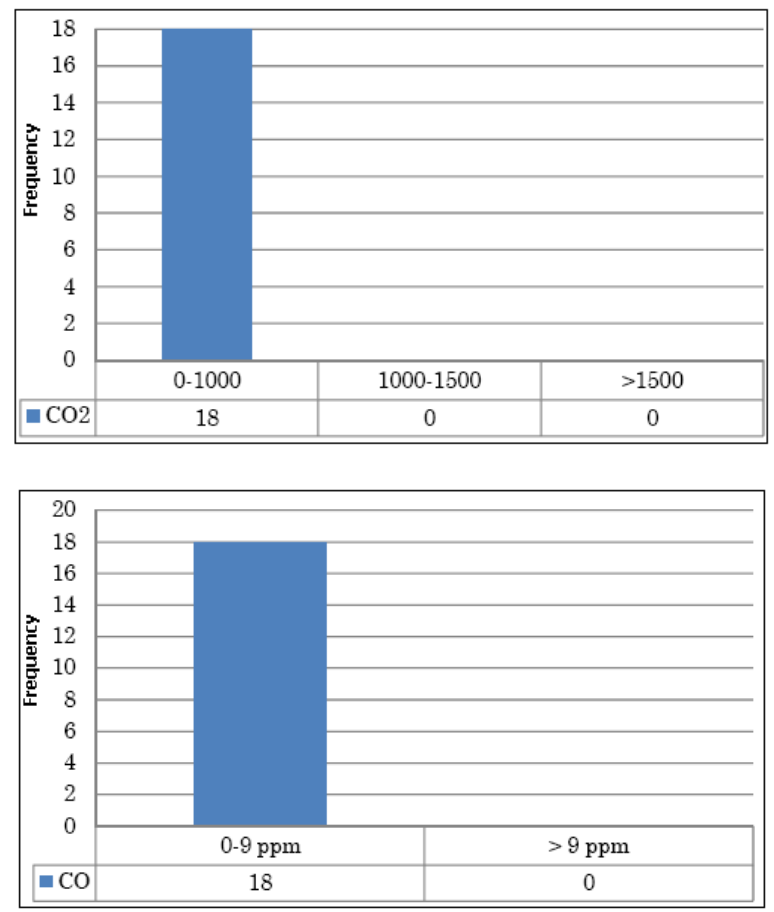

Figure 7: Frequency distributions of the $\mathrm{CO}_{2}$ and $\mathrm{CO}$ index inside the bus.

\section{Conclusions}

The obtained results give different indications for passengers using the subway and those that use the bus. As matter of fact, inside the bus, the indices indicate that there are thermo-hygrometric conditions that may cause heat stroke and feeling unwell in passengers due to the absence of an air conditioning system.

Inside the subway carriages there is an air conditioning system, consequently the situation is the opposite to that of the previous one. As matter of fact, the passengers suffer physiological discomfort (cold sensation) due to the low temperatures reached inside the carriages that in many measurements were lower than $26^{\circ} \mathrm{C}$.

A further element of discomfort that can cause health problems for the passengers are the thermal gradients. In the subway, with reference to the external air temperature, the thermal gradients, in many cases, were greater than $10^{\circ} \mathrm{C}$. It would be desirable to have a better control of the temperature inside the vehicles (bus and metro) in order to improve the comfort for passengers and, above all, to avoid possible health hazards. The improvement of thermohygrometric comfort can contribute, in combination with other factors, to increasing the use of public transport by citizens. 


\section{References}

[1] R.de Dear, K.L. Ebi, D. Scott, S. Sheridan, M. D. Schwartz Biometeorology for Adaptation to Climate Variability and Change, Springer, 2009.

[2] J.M. Masterton and F.A. Richardson o, Canada's Atmospheric Environment Service, 1979.

[3] ISO. Moderate thermal environments - determination of the PMV and PPD indices and specification of the conditions for thermal comfort. ISO 7730. Geneve: International Organization for Standardization; 1998.

[4] ASHRAE, (2004). ASHRAE Standard 55-2004. Thermal environmental conditions for human occupancy, American Society of heating ventilation and air conditioning.

[5] Abbaspour, M.; Jafari, M. J.; Mansouri, N.; Moattar, F.; Nouri, N.; Allahyari, M., (2008). Thermal comfort evaluation in Tehran metro using Relative Warmth Index. Int. J. Environ. Sci. Tech., 5 (3), 297-304.

[6] ASHRAE, (1989). ASHRAE standards 62-1989, Ventilation for acceptable indoor air quality, American Society of heating ventilation and air conditioning.

[7] ASHRAE, (1989). Addendum to standard 62-1989: New ventilation rates proposal, American Society of heating ventilation and air conditioning, $10-11$.

[8] Chadderton, D., (1997). Air Conditioning, a practical introduction, Thomson Science professional, 2nd. Ed., Chapter 2, 37-67.

[9] www.cpsc.gov/cpscpub/pubs/iaq.html

[10] Air Quality Science IAQ Resource Center (Aerias). 2005. Carbon Dioxide: A Common Indoor Air Pollutant. www.Aerias.com 